|| ISSN(online): 2589-8698 || ISSN(print): 2589-868X || International Journal of Medical and Biomedical Studies Available Online at www.ijmbs.info

Volume 3, Issue 2; February: 2019; Page No. 102-113

PubMed (National Library of Medicine ID: 101738825)

Index Copernicus Value 2017: 40.03

\title{
EFFECTS OF GROUP-BASED MULTICOMPONENT COGNITIVE TRAINING ON COGNITION, MOOD AND INSTRUMENTAL ACTIVITIES OF DAILY LIVING AMONG OLDER PEOPLE LIVING IN THE COMMUNITY
}

\author{
Patsri Srisuwan ${ }^{1 *}$, Daochompu Nakawiro ${ }^{2}$, Sirinthorn Chansirikarnjana ${ }^{3}$, Orawan Kuha ${ }^{4}$, Sayan \\ Janbumrung ${ }^{5}$, Theeratarn Thammachot ${ }^{5}$ \\ ${ }^{1}$ Outpatient and Family Medicine Department, Phramongkutklao Hospital, Bangkok, Thailand \\ ${ }^{2}$ Department of Psychiatry, Ramathibodi Hospital, Mahidol University, Bangkok, Thailand \\ ${ }^{3}$ Department of Medicine, Ramathibodi Hospital, Mahidol University, Bangkok, Thailand \\ ${ }^{4}$ Institute of Geriatric Medicine, Ministry of Public Health, Nonthaburi, Thailand \\ ${ }^{5}$ Phramongkutklao Geriatric Clinic, Phramongkutklao Hospital, Bangkok, Thailand
}

Article Info: Received 29 January 2019; Accepted 21 February. 2019

Cite this article as: Srisuwan, P., Nakawiro, D., Chansirikarnjana, S., Kuha, O., Janbumrung, S., \& Thammachot, T. (2019). EFFECTS OF GROUP-BASED MULTICOMPONENT COGNITIVE TRAINING ON COGNITION, MOOD AND INSTRUMENTAL ACTIVITIES OF DAILY LIVING AMONG OLDER PEOPLE LIVING IN THE COMMUNITY. International Journal of Medical and Biomedical Studies, 3(2).

DOI: https://doi.org/10.32553/ijmbs.v3i2.107

Address for Correspondence: Patsri Srisuwan, Outpatient and Family Medicine Department, Phramongkutklao Hospital, Bangkok, Thailand

Conflict of interest: No conflict of interest.

\section{Abstract}

The present study aimed to assess the effectiveness of a multicomponent cognitive training using training of executive functions, attention, memory and visuospatial functions (TEAM-V) Program on cognition, mood and instrumental activities of daily living (IADL) among healthy older adults living in community. Using a single-blinded randomized controlled design, 80 participants were randomized to the TEAM-V or control group. The TEAM-V intervention was conducted for 5 sessions, with 2-week intervals between each session. The Thai version of the Montreal Cognitive Assessment (MoCA), the Alzheimer's Disease Assessment Scale-Cognitive Subscale (ADAS-cog), the Thai version of the Hospital Anxiety and Depression Scale (HADS) and the Chula ADL were used to assess at baseline and 6 months. Participants receiving the TEAM-V Program were associated with significant improvement in MoCA $(P=0.03)$, word recall task $(P=0.01)$ and word recognition task $(P=0.01)$ scores (subtests of ADAS-cog) versus the control. Both anxiety and depression scores decreased in the intervention group (mean \pm SD: $-0.20 \pm 2.15$ and $-0.43 \pm 2.17$, respectively). In contrast, both anxiety and depression scores increased in the control group (mean \pm SD: $0.59 \pm 1.98$ and $0.76 \pm 2.17$, respectively). IADL scores increased in the intervention group but not in the control group (mean \pm SD: $0.13 \pm 0.61$ and $-0.05 \pm 0.33$, respectively). The TEAM-V Program helped to improve global cognitive function, memory, reduce anxious and depressive symptoms and enhance IADL among healthy older people.

Key words: activities of daily livings, cognitive training, mood, older adults 


\section{Introduction:}

Cognitive training is based on the idea that the brain functions, even in old age, can be improved. The training uses guided practice on a set of tasks related to memory, executive function, attention or other brain functions. The goals of the training are to improve or maintain ability in specific cognitive domains [1]. This training can take many formats. For example, it can be conducted among individuals or in groups, either single, e.g., memory or multiple, e.g., memory and executive functions. Moreover, the approach might consider a bottom-up training, e.g., enhancing sensory and perceptual skills to improve higher order processing or topdown, e.g., target mechanisms of cognitive control to improve the systematic problemsolving approach [2]. Many studies have shown that cognitive-based interventions such as group activities and problem solving, reading and computer-based training are associated with better cognitive function and reduced risk of cognitive decline and dementia among healthy older people $[3,4]$. Although several studies have proved the positive effects of cognitive training among healthy older adults concerning cognition [5], little attention has been paid to the effect of cognitive training on mood although depression and anxiety are known to negatively impact cognition and are related to early cognitive decline [6]. Interestingly, cognitive training among people at risk of dementia such as depression and/or minor neurocognitive disorder showed improvements in cognitive and mood functions [7]. In addition, one recent study revealed cognitive training among older people with minor neurocognitive disorder could protect against a decline in mental abilities such as depression and anxiety [8]. However, some cognitive training programs used advanced or expensive technology that would be difficult to apply to some locations such as rural areas in Thailand. In addition, no consensus has been reached regarding which specific cognitive trainings are more effective such as multidomain versus uni-domain; group versus individual settings or number of session.
In Thailand, studies pertaining to cognitive training are conducted mostly among patients with Alzheimer's Disease and only regarding specific aspects of cognition such as memory $[9,10]$. In our previous study, a training of executive functions, attention, memory and visuospatial functions (TEAM-V) Program was developed for group-based multicomponent cognitive training. A top-down approach was used for cognitive training in people with mild neurocognitive disorder. The results showed that the intervention group had significantly higher scores than the control group for verbal fluency category [11]. Furthermore, nearly $89.5 \%$ and $88.5 \%$ of participants reported that the training program had benefit and practical strategies for daily living, respectively [12]. In addition, the program helped to improve global cognitive function and reduce depressive symptoms [13].

The aim of the present study was to assess the effectiveness of a multicomponent cognitive training using TEAM-V Program on cognition, mood and instrumental activities of daily living (IADL) among healthy older adults living in community. The hypothesis was that individuals receiving the program will have improved cognitive function, mood and IADL outcomes compared with those not receiving the program.

\section{MATERIALS AND METHODS}

\section{Eligibility criteria and recruitment methods:}

This experimental study was a part of the Cognitive Training Program in Healthy Older People Project, conducted by the research team from The Institute of Geriatrics Medicine, Thailand. In this project 217 participants were enrolled from across the four regions of the country. Research sites in each region were led by medical professionals such as geriatrics nurses, receiving training during a four-day workshop, held in February 2017, by the main research team. The workshop covered both clinical and instrumental assessment of cognitive function and method of delivering the cognitive training program. 
Participants in this study were from central Thailand; we recruited 98 healthy older participants who visited the Geriatric Clinic, Outpatient Department, Phramongkutklao Hospital, Bangkok, Thailand from April to May 2017. The enrolled participants were aged $>60$ years and willing to participate in all five activities. The exclusion criteria were: the Thai version of the Hospital Anxiety and Depression Scale (HADS) score higher than 11 on anxiety or depression [14], the Thai version of Montreal Cognitive Assessment (MoCA) score less than 26 (subjects who achieve scores less than 26 were suspected minor neurocognitive disorder or dementia) [15], having any conditions affecting participation in program activities, e.g. balancing problems, hearing impairment as well as any psychiatric diseases and neurological problems such as stroke. This study was approved by the Institutional Review Board of the Royal Thai Army Medical Department Ethics Committee as instituted by the Declaration of Helsinki, and all participants were required to provide written informed consent before enrolling.

\section{Study design:}

The study employed a single-blinded randomized controlled design. Fig 1 illustrates the timeline of the assessment and intervention procedures. Participants were randomly allocated to either the intervention or control group on 1:1 basis using simple randomization methods. Randomization was conducted by a Clinical Trials Manager who was blinded to patient status throughout the study. Independent teams conducted the administration of the cognitive measures and the training sessions. After providing informed consent, participants were randomly assigned to the experimental or control group. All subjects were given an explanation about the protocol of their allocated group. Those who refused to fully attend all required activities were excluded from the study. Recruitment was continuously conducted until the number of participants reached 40 for each group.

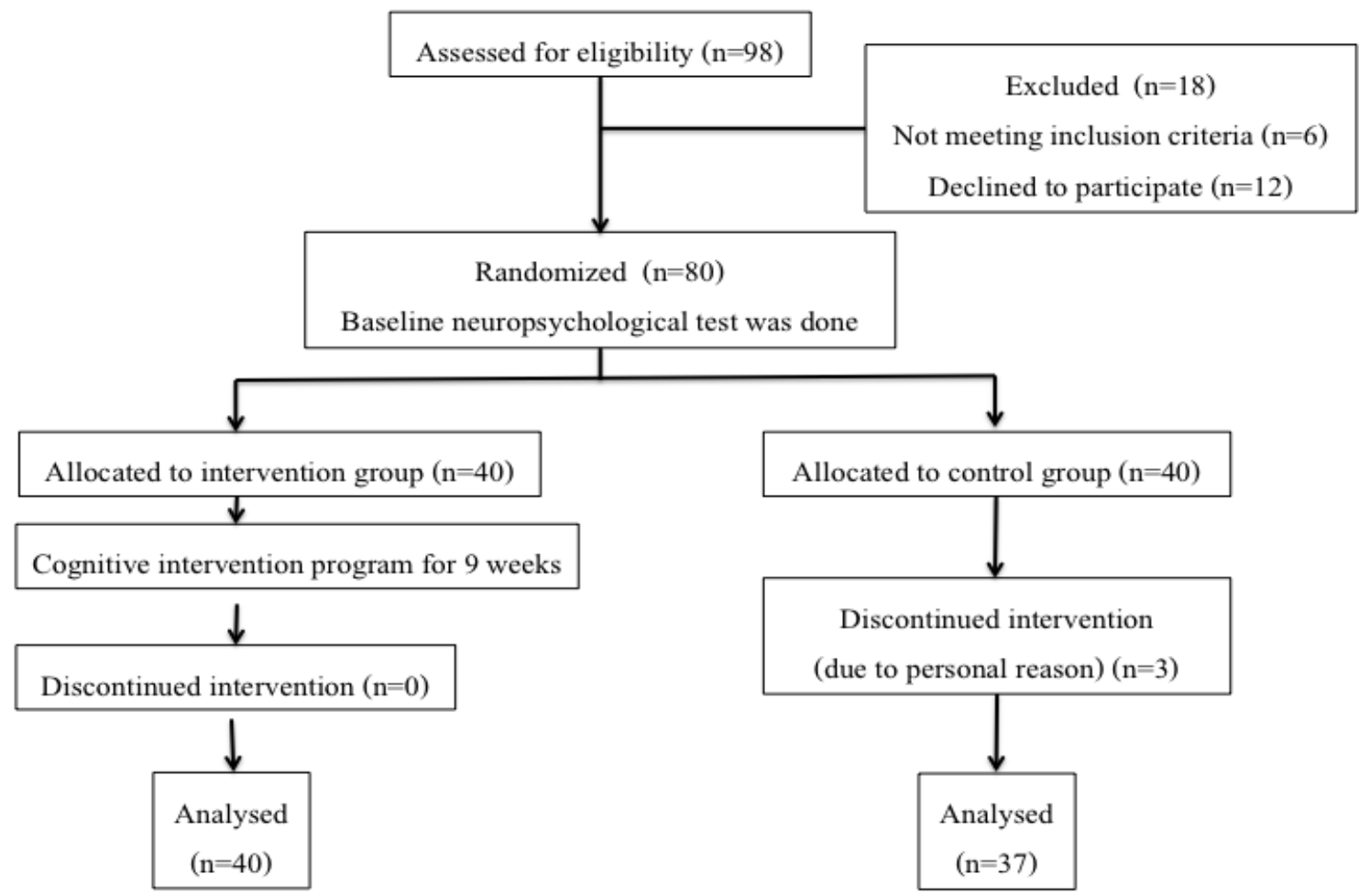

Figure 1: Flow chart of the cognitive intervention program participants. 


\section{Description of the intervention:}

The control group received standard clinical care from their usual health care professionals. The intervention group received cognitive training using the TEAM- $V$ Program constituting a multidomain cognitive training program consisting of training of executive function, attention, memory and visuospatial function. The training was held from May to July 2017, 5 sessions, with a 2-week interval between each session and 120 minutes per session. Each session involved training of different domains of cognition. The details of each session are shown in Table 1.

Table 1: The TEAM-V program cognitive training activities.

\begin{tabular}{|c|c|c|c|c|}
\hline Sessions & $\begin{array}{l}\text { Type/main } \\
\text { domain } \\
\text { training }\end{array}$ & $\begin{array}{l}\text { Contents of } \\
\text { training }\end{array}$ & $\begin{array}{l}\text { Example of activities in } \\
\text { class }\end{array}$ & Example of homework \\
\hline 1 & Attention & $\begin{array}{l}\text { Switching, } \\
\text { selective and } \\
\text { sustained } \\
\text { attentions }\end{array}$ & $\begin{array}{l}\text { Listening carefully a } \\
\text { story and a song as a } \\
\text { distractor, answers the } \\
\text { detail of the story }\end{array}$ & $\begin{array}{l}\text { Identify internal and } \\
\text { external distracters in } \\
\text { daily living }\end{array}$ \\
\hline 2 & Memory & $\begin{array}{l}\text { Short-term } \\
\text { memory }\end{array}$ & $\begin{array}{l}\text { Practicing mental } \\
\text { visualization } \\
\text { techniques to } \\
\text { memorize information } \\
\text { such as names and } \\
\text { objects }\end{array}$ & $\begin{array}{l}\text { Memory techniques } \\
\text { using in real life such } \\
\text { techniques to remember } \\
\text { of shopping lists }\end{array}$ \\
\hline 3 & Memory & $\begin{array}{l}\text { Short and } \\
\text { long-term } \\
\text { memory }\end{array}$ & $\begin{array}{l}\text { Listening a story and } \\
\text { practicing strategies } \\
\text { such as mnemonics, } \\
\text { mind map and picture } \\
\text { to improve memory }\end{array}$ & $\begin{array}{l}\text { Short-term memory: } \\
\text { summarized news with } \\
\text { mnemonics, mind map } \\
\text { and picture } \\
\text { Long-term memory: } \\
\text { autobiography }\end{array}$ \\
\hline 4 & Visuospatial & $\begin{array}{l}\text { Spatial- } \\
\text { temporal } \\
\text { reasoning }\end{array}$ & $\begin{array}{l}\text { Identify number of } \\
\text { overlap descriptions, } \\
\text { analyze a figure and } \\
\text { reproduce it }\end{array}$ & $\begin{array}{l}\text { Draw a map from home } \\
\text { to hospital }\end{array}$ \\
\hline 5 & $\begin{array}{l}\text { Executive } \\
\text { function }\end{array}$ & $\begin{array}{l}\text { Management } \\
\text { skills }\end{array}$ & $\begin{array}{l}\text { Planning and doing } \\
\text { sandwich with limited } \\
\text { resources }\end{array}$ & - \\
\hline
\end{tabular}

\section{Neuropsychological testing for baseline} assessment and outcome measures:

The primary outcome was change of cognitive function of participants. To identify changes of global cognitive function, we applied the Thai version of the MoCA to assess various domains of cognition including attention, executive function, memory, language, visuospatial skills, conceptualization, calculation and orientation.
To identify changes of different domains of cognitive function, we applied the main subtests of Alzheimer's Disease Assessment ScaleCognitive subscale (ADAS-cog) as described below $[16,17]$.

Word recall task was administered to measure immediate recall memory. The participants were given three trials to remember a list of ten words in block letters on white cards. Scoring was one 
point for each word if the participant did not remember it. Average total learning over three trials was examined.

Constructional praxis was used to assess visuospatial function. The participants were asked to copy a cube on a piece of paper. Scoring was one point for each error including not threedimensional, the front face in the incorrect orientation, internal lines drawn incorrectly between corners and opposite sides of face unparalleled or unequal in size.

The number of cancellations from part $A$ to $C$ was considered to be a general measure of attention. The participants were asked to cross off as many targets as possible in 45 seconds. Scoring for part A constituted the total correct numbers crossed off, and for part B constituted the total incorrect numbers crossed off and for part $C$ involved the number of times to be reminded to completed the task.

Delayed recall was administered to measure delayed recall memory. The participants were asked to recall as many words as possible from the ten words presented during the word recall task.

The maze test was used to assess executive function. The participants were asked to find the route from the start to the exit of the seven mazes on the paper. The time needed to complete the task was recorded.

The word recognition task was considered to be a general measure of retrieval and retention of the memory process. The participants were given three trials to remember a list of 12 words in block letter printed on white cards. Then the participants were given another set of words, with some of the words were printed on the cards, but some of the words were not printed on the cards. Scoring was one point for each word when the participant did not remember it. The average total learning over three trials was examined.

Secondary outcomes comprised those described below.
1. The Thai version of HADS c comprised an anxiety and depression assessment tool. It consisted of 14 question; 7 questions for anxiety and 7 questions for depression. Each item had been answered by the patient on a four point ( 0 3) response category. Scores ranged from 0 to 21 for anxiety and 0 to 21 for depression. A score of 11 or more was generally considered to indicate anxiety or depression [14].

2. The Chula ADL Index was the Thai version and was used in this study under the term IADL, which assessed the ability to perform complex tasks such as shopping and housekeeping. The IADL indicated the ability to exist in the community independently, including the ability to perform daily tasks. Scores ranged from 0 to 9 [18].

\section{Statistical Analyses:}

Statistical analyses were performed using Statistical Package for the Social Sciences, Version 23.0 for Windows (SPSS, Chicago, IL, USA). Unless otherwise stated, all values were presented as mean \pm SD. Demographic comparisons between the intervention and control groups used the Fisher's exact test, Independent $\mathrm{t}$-test and Mann-Whitney $\mathrm{U}$ test. Comparisons of neurological test scores before and after cognitive intervention were conducted using the Paired t-test, Wilcoxon Signed Ranks Test, Independent t-test and Mann-Whitney $U$ test. Comparisons of HADS, Chula IADL scores before and after cognitive intervention were conducted using the Wilcoxon Signed Ranks Test and Mann-Whitney $U$ test. A value of $P<0.05$ was considered statistically significant.

\section{RESULTS}

Demographic analyses and baseline characteristics

A detailed flow chart of the present study is shown in Fig 1 . Of the 98 participants referred to the trial, 80 participants met eligibility criteria and completed base line assessment. Of this group, 40 were randomized to the intervention group and 40 were randomized to the control group. Three participants in the control group 
Patsri Srisuwan et al, International Journal of Medical and Biomedical Studies (IJMBS)

did not complete the study. Therefore, the participants' dropout rate was $3.75 \%$.

Patients' characteristics at baseline for each group are shown in Table 2. On average, participants were young-old (mean age $66.23 \pm 4.64$ years in the intervention group vs. $65.11 \pm 4.08$ years in the control group). Most participants were female ( $80 \%$ vs. $73 \%)$, most had obtained a bachelor's degree (63\% vs. $59 \%)$, had a chronic medical conditions ( $83 \%$ vs. $89 \%)$, exercised regularly (95\% vs. $79 \%$ ), and had leisure activities ( $85 \%$ vs. $92 \%$ ). No significant intergroup differences were found between age, gender, marital status, level of education, existing medical conditions, lifestyle such as exercise, leisure activities and participation in social activities, body mass index and the scores of MoCA, subtests of ADAS-Cog, HADS and IADL at baseline data.

Table 2: Participant characteristics at baseline.

\begin{tabular}{|c|c|c|c|}
\hline Characteristic & $\begin{array}{l}\text { Intervention group } \\
(n=40) \\
\text { mean } \pm \text { SD }\end{array}$ & $\begin{array}{l}\text { Control group } \\
(n=37) \\
\text { mean } \pm S D \\
\end{array}$ & P-value \\
\hline Age (years) & $66.23 \pm 4.64$ & $65.11 \pm 4.08$ & $0.267^{* *}$ \\
\hline Male, n (\%) & $8(20 \%)$ & $9(23.68 \%)$ & 0.648 \\
\hline Marital status & & & $0.351^{*}$ \\
\hline Single, $\mathrm{n}(\%)$ & $8(20 \%)$ & $6(16.22 \%)$ & \\
\hline Married, n (\%) & $24(60 \%)$ & $24(64.86 \%)$ & \\
\hline Other (Widowed, separated, divorced), n (\%) & $8(20 \%)$ & $7(18.92 \%)$ & \\
\hline Highest level of education & & & $0.966^{*}$ \\
\hline $7-12$ years, $n(\%)$ & $1(2.5 \%)$ & $1(2.7 \%)$ & \\
\hline Associate's degree, n (\%) & $2(5 \%)$ & $3(8.11 \%)$ & \\
\hline Bachelor's degree, n (\%) & $25(62.5 \%)$ & $22(59.46 \%)$ & \\
\hline Graduate degree, $\mathrm{n}(\%)$ & $12(30 \%)$ & $11(29.73 \%)$ & \\
\hline Chronic medical conditions, $\mathrm{n}(\%)$ & $33(82.5 \%)$ & $33(89.19 \%)$ & 0.402 \\
\hline Diabetes, n (\%) & $4(10 \%)$ & $0(0 \%)$ & $0.116^{*}$ \\
\hline Hypertension, n (\%) & $12(30 \%)$ & $17(45.95 \%)$ & 0.149 \\
\hline Dyslipidemia, n (\%) & $21(52.5 \%)$ & $18(48.65 \%)$ & 0.736 \\
\hline Regular exercise, $\mathrm{n}(\%)$ & $38(95 \%)$ & $30(78.95 \%)$ & $0.079^{*}$ \\
\hline Having leisure activities, n (\%) & $34(85 \%)$ & $35(92.1 \%)$ & $0.266^{*}$ \\
\hline Participation in social activities, $\mathrm{n}(\%)$ & $26(65 \%)$ & $28(75.68 \%)$ & 0.306 \\
\hline Body mass index & $24.03 \pm 3.42$ & $24.54 \pm 3.54$ & $0.526^{* *}$ \\
\hline MoCA & $27.83 \pm 1.34$ & $27.62 \pm 1.53$ & $0.536^{* *}$ \\
\hline Word recall task & $2.99 \pm 1.28$ & $2.70 \pm 1.00$ & $0.265^{* *}$ \\
\hline Construction praxis & $0.25 \pm 0.71$ & $0.27 \pm 0.77$ & $0.925^{* * *}$ \\
\hline Number cancellation part A & $25.6 \pm 6.54$ & $27.32 \pm 6.54$ & $0.253^{* * *}$ \\
\hline Number cancellation part B & $0.03 \pm 0.16$ & $0.14 \pm 0.82$ & $0.408^{* * *}$ \\
\hline Number cancellation part C & $0.00 \pm 0.00$ & $0.00 \pm 0.00$ & NA \\
\hline Delayed recall & $2.45 \pm 1.40$ & $2.32 \pm 1.49$ & $0.710^{* * *}$ \\
\hline Maze test & $58.72 \pm 26.38$ & $64.32 \pm 36.39$ & $0.862^{* * *}$ \\
\hline Word recognition task & $5.34 \pm 2.17$ & $5.01 \pm 1.83$ & $0.474^{* *}$ \\
\hline HADS: Anxiety & $3.53 \pm 2.21$ & $4.57 \pm 2.43$ & $0.057^{* * *}$ \\
\hline HADS: Depression & $2.75 \pm 2.31$ & $2.89 \pm 2.11$ & $0.695^{* * *}$ \\
\hline IADL & $7.78 \pm 0.62$ & $7.95 \pm 0.23$ & $0.160^{* * *}$ \\
\hline
\end{tabular}


Data presented as mean + standard deviation, Chi-square test for categorical data, 'Fisher's exact test. ${ }^{* *}$ Independent t-test. ${ }^{* * *}$ Mann-Whitney $U$ test. MoCA, the Thai version of Montreal Cognitive Assessment; HADS, the Thai version of Hospital Anxiety and Depression Scale; IADL, the Chula ADL Index; SD, standard deviation; NA, not applicable

\section{Effects of intervention on cognitive function:}

Table 3 illustrates baseline and follow-up data of neuropsychological tests for the intervention and control groups. For MoCA, scores at the baseline survey in the intervention group (27.83 \pm 1.34$)$ increased significantly after the cognitive training $(28.43 \pm 1.55, P=0.032)$. For the word recall task, scores at the baseline survey in the intervention group (2.99 \pm 1.28$)$ were significant decreased after the cognitive training $(2.43 \pm 1.21, P=0.016)$. Scores of the word recognition task showed a significant reduction between pre- and postparticipation in the intervention group (5.34 \pm 2.17 vs. $4.35 \pm 1.98, P$ $=0.010)$. No significant differences were found in either group before and after the cognitive training in the measure of the construction praxis, the number of cancellations, delayed recall and the maze test.

Table 3: Results of neuropsychological test.

\begin{tabular}{|c|c|c|c|c|}
\hline & & $\begin{array}{l}\text { Intervention group } \\
(\mathrm{n}=40) \\
\text { mean } \pm \text { SD }\end{array}$ & $\begin{array}{l}\text { Control group } \\
(n=37) \\
\text { mean } \pm S D\end{array}$ & $\begin{array}{l}\text { Intergroup } \\
\text { P-value }\end{array}$ \\
\hline \multirow[t]{4}{*}{ MoCA } & Baseline & $27.83 \pm 1.34$ & $27.62 \pm 1.53$ & $0.48^{* * *}$ \\
\hline & Month 6 & $28.43 \pm 1.55$ & $27.95 \pm 1.72$ & \\
\hline & Change & $0.60 \pm 1.71$ & $0.32 \pm 1.75$ & \\
\hline & Intragroup P-value & $0.03^{*}$ & $0.26^{*}$ & \\
\hline \multirow[t]{4}{*}{ Word recall task } & Baseline & $2.99 \pm 1.28$ & $2.70 \pm 1.00$ & $0.33^{* * *}$ \\
\hline & Month 6 & $2.43 \pm 1.21$ & $2.43 \pm 1.06$ & \\
\hline & Change & $-0.57 \pm 1.42$ & $-0.27 \pm 1.27$ & \\
\hline & Intragroup P-value & $0.01^{*}$ & $0.21^{*}$ & \\
\hline \multirow{4}{*}{$\begin{array}{l}\text { Construction } \\
\text { praxis }\end{array}$} & Baseline & $0.25 \pm 0.71$ & $0.27 \pm 0.77$ & $0.14^{* * * *}$ \\
\hline & Month 6 & $0.13 \pm 0.40$ & $0.46 \pm 0.84$ & \\
\hline & Change & $-0.13 \pm 0.76$ & $0.19 \pm 0.91$ & \\
\hline & Intragroup P-value & $0.366^{* *}$ & $0.24^{* *}$ & \\
\hline \multirow{4}{*}{$\begin{array}{l}\text { Number } \\
\text { cancellation part } \\
\text { A }\end{array}$} & Baseline & $25.6 \pm 6.54$ & $27.32 \pm 6.54$ & $0.304^{* * *}$ \\
\hline & Month 6 & $25.3 \pm 6.06$ & $25.78 \pm 5.73$ & \\
\hline & Change & $-0.30 \pm 5.18$ & $-1.54 \pm 5.33$ & \\
\hline & Intragroup P-value & $0.716^{*}$ & $0.087^{*}$ & \\
\hline \multirow{4}{*}{$\begin{array}{l}\text { Number } \\
\text { cancellation part } \\
\text { B }\end{array}$} & Baseline & $0.03 \pm 0.16$ & $0.14 \pm 0.82$ & $0.543^{* * * *}$ \\
\hline & Month 6 & $0.02 \pm 0.16$ & $0.00 \pm 0.00$ & \\
\hline & Change & $0.00 \pm 0.23$ & $-0.14 \pm 0.82$ & \\
\hline & Intragroup P-value & $1.000^{* *}$ & $0.317^{* *}$ & \\
\hline \multirow[t]{2}{*}{$\begin{array}{l}\text { Number } \\
\text { cancellation part } \\
\text { C }\end{array}$} & Baseline & $0.00 \pm 0.00$ & $0.00 \pm 0.00$ & $1.000^{* * * *}$ \\
\hline & Month 6 & $0.00 \pm 0.00$ & $0.00 \pm 0.00$ & \\
\hline
\end{tabular}


Patsri Srisuwan et al, International Journal of Medical and Biomedical Studies (IJMBS)

\begin{tabular}{|l|l|l|l|l|}
\hline & Change & $0.00 \pm 0.00$ & $0.00 \pm 0.00$ & \\
\hline & Intragroup P-value & $1.000^{* *}$ & $1.000^{* *}$ & \\
\hline Delayed recall & Baseline & $2.45 \pm 1.40$ & $2.32 \pm 1.49$ & $0.24^{* * * *}$ \\
\hline & Month 6 & $2.05 \pm 1.72$ & $2.30 \pm 1.56$ & \\
\hline & Change & $-0.40 \pm 1.75$ & $-0.03 \pm 2.05$ & \\
\hline & Intragroup P-value & $0.10^{* *}$ & $0.94^{* *}$ & \\
\hline Maze test & Baseline & $58.72 \pm 26.38$ & $64.32 \pm 36.39$ & $0.15^{\mathrm{d}^{* * * *}}$ \\
\hline & Month 6 & $57.87 \pm 17.97$ & $53.11 \pm 19.62$ & \\
\hline & Change & $-0.85 \pm 27.09$ & $-11.21 \pm 27.19$ & \\
\hline $\begin{array}{l}\text { Word } \\
\text { recognition task }\end{array}$ & Intragroup P-value & $0.99^{* *}$ & $0.051^{* *}$ & \\
\hline & Baseline & $5.34 \pm 2.17$ & $5.01 \pm 1.83$ & $0.46^{* * *}$ \\
\hline & Month 6 & $4.35 \pm 1.98$ & $4.39 \pm 1.60$ & \\
\hline & Change & $-0.98 \pm 2.29$ & $-0.62 \pm 2.06$ & \\
\hline & Intragroup P-value & $0.01^{*}$ & $0.07^{*}$ & \\
\hline
\end{tabular}

${ }^{*}$ Paired t-test. ${ }^{* *}$ Wilcoxon Signed Ranks Test. ${ }^{* * *}$ Independent t-test. ${ }^{* * * *}$ Mann-Whitney U test. Change, Month 6-Baseline; MoCA, the Thai version of Montreal Cognitive Assessment; SD, standard deviation

Effects of intervention on mood and IADL:

Table 4 illustrates baseline and follow-up data of HADS and IADL for the intervention and control groups. For HADS, both anxiety and depression scores decreased in the intervention group (mean \pm SD: $-0.20 \pm 2.15$ and $-0.43 \pm 2.17$, respectively). In contrast, both anxiety and depression scores increased in the control group (mean \pm SD: $0.59 \pm 1.98$ and $0.76 \pm 2.17$, respectively). Moreover, depression scores significantly increased in the control group but not in the intervention group $(P=0.039$ and $P=0.259$, respectively). Compared to the baseline level, IADL scores increased in the intervention group but not in the control group (mean \pm SD: $0.13 \pm 0.61$ and $-0.05 \pm 0.33$, respectively). However, no significant changes were observed in the intervention and control groups $(P=0.206$ and $P=0.317$, respectively).

Table 4: Results of Hospital Anxiety and Depression Scale and Instrumental Activities of Daily Living Scale.

\begin{tabular}{|l|l|l|l|l|}
\hline & & $\begin{array}{l}\text { Intervention group } \\
(\mathrm{n}=40) \\
\text { mean } \pm \text { SD }\end{array}$ & $\begin{array}{l}\text { Control group } \\
(\mathrm{n}=38) \\
\text { mean } \pm \text { SD }\end{array}$ & $\begin{array}{l}\text { Intergroup } \\
\text { P-value }\end{array}$ \\
\hline HADS: Anxiety & Baseline & $3.53 \pm 2.21$ & $4.57 \pm 2.43$ & $0.06^{* *}$ \\
\hline & Month 6 & $3.32 \pm 2.45$ & $5.16 \pm 2.94$ & \\
\hline & Change & $-0.20 \pm 2.15$ & $0.59 \pm 1.98$ & \\
\hline HADS: Depression & Intragroup P-value & $0.38^{*}$ & $0.09^{*}$ & \\
\hline & Baseline & $2.75 \pm 2.31$ & $2.89 \pm 2.11$ & $0.05^{* *}$ \\
\hline & Month 6 & $2.33 \pm 1.82$ & $3.65 \pm 2.51$ & \\
\hline IADL & Change & $-0.43 \pm 2.17$ & $0.76 \pm 2.17$ & \\
\hline & Intragroup P-value & $0.25^{*}$ & $0.03^{*}$ & \\
\hline & Baseline & $7.78 \pm 0.62$ & $7.95 \pm 0.23$ & $0.13^{* *}$ \\
\hline & Month 6 & $7.90 \pm 0.30$ & $7.89 \pm 0.31$ & \\
\hline & Change & $0.13 \pm 0.61$ & $-0.05 \pm 0.33$ & \\
\hline & Intragroup P-value & $0.20^{*}$ & $0.31^{*}$ & \\
\hline
\end{tabular}

"Wilcoxon Signed Ranks Test. ${ }^{* *}$ Mann-Whitney U test. Change, Month 6 - Baseline; HADS, the Thai version of Hospital Anxiety and Depression Scale; IADL, the Chula ADL Index; SD, standard deviation 


\section{DISCUSSION}

The results of the present study showed that a multicomponent cognitive training using the TEAM-V Program significantly benefitted global cognitive function and memory. Although intergroup differences did not achieve statistical significance, mood and IADL scores also showed improvement in the intervention group.

The improvement of cognitive function may be explained by the fact that cognitive training enhances resting state neural activity and connectivity [19], increasing the blood supply to these regions via neurovascular coupling [20]. In the intervention group, our findings demonstrated significant improvements in immediate recall memory and retrieval memory processes, which were observed on decreasing errors of word recall task scores and word recognition task scores. However, visuospatial, attention and executive functions did not improve significant. Memory problems are common concerns for general older adults. Therefore, the TEAM-V Program provided two sessions for memory training, but other domains had one session per domain. For example, the cognitive training of executive function with breakfast cooking task by Wang and colleagues lasted five weeks with one session weekly. The training session lasted for about one hour. Participants had to switch, update and plan to control the cooking of several foods while concurrently setting the table. The cooking training task significantly improved participants' executive function [21]. Compared with the TEAM-V Program, executive function training provided only one session of planning and making a sandwich with limited resources. Therefore, the duration of training and complexity of tasks in the session may not have been sufficient to significantly improve executive function. Overall, many positive studies used higher intensity cognitive training (often more than $150 \mathrm{~min}$ weekly) [2,22] more than the TEAM-V Program.

The control group had both higher mean scores of Thai HADS in anxiety and depression scores compared with their baseline scores. The depression scores were significantly higher. On the other hand, the intervention group had both lower mean scores of Thai HADS in anxiety and depression scores. Thus, the training program helped to improve the mental health of participants. Interaction with others during group activities could have helped participants improve their self-esteem and enjoy activities that would have helped them to achieve better mental health. Recent publications have consistently shown cognitive trainings increased positive mood among healthy older adults [23], at risk of dementia [24] and people with Alzheimer's Disease [25].

In the present study, no significant changes were found in IADL scores in both intervention and control groups, but trend was found towards improvement in the intervention group. Possibly, successful completion of ADL depends upon having the cognitive skills, e.g., memory and executive function, necessary to accomplish the tasks [26]. However, our study involved short term follow-up and the sample size was insufficient to demonstrate significant improvement of ADL. An experimental study among 2,832 healthy older adults with ten years follow-up found that in three intervention groups of cognitive training by memory training, reasoning training or speed training was reported as less difficult regarding IADL compared with the control group [27]. Cognitive training may improve IADL among people with dementia more than among healthy older adults. In an experimental study of cognitive training among healthy older adults, minor neurocognitive disorders and Alzheimer's Disease also found IADL were significantly improve in the intervention group of Alzheimer's Disease, but not in the group comprising minor neurocognitive disorders and healthy older adults [28].

Some limitations were observed in the present study. It should be note that in both groups the percentage of females was greater than that of males. The use of treatment-as-usual control had 
limited interpretation of the training effects found. An improved design such as including active control may have better clarified the nature of the training effects found. Possibly, the improvements in global cognition, memory and depression may have been attributed to nonspecific effects from factors such as other interventions that may have formed part of a patient's routine management or cognitive training undertaken by participants of their own accords. In addition, sample size and longitudinal follow-up (at least 7-14 years) [29] could be extended in future studies to strengthen the study findings. Moreover, future research should include holistic assessments such as lifestyle factors such as physical exercise [30], brain imagery techniques and biomarkers to identify the specific aspects related to cognitive improvement regarding cognitive training.

Given the results of the present study, it could be concluded that group-based multicomponent cognitive training using the TEAM-V Program had a potential in helping to improve cognitive function, to reduce anxiety and depression and to enhance function of IADL among healthy older adults.

\section{ACKNOWLEDGEMENTS}

The authors would like to express our gratitude to the participants and PMK aging team in Geriatric Clinic, Phramongkutklao Hospital. We also would like to thank the Institute of Geriatric Medicine for allowing the research team to be a part of the larger study and conducted project activities in the Central region of Thailand. We also thank Ms. Worarachanee Imjaijitt for statistical analysis. The research project was partially supported by The Development Potentials of Thai People Project.

\section{Disclosure statement:}

The authors declare no conflicts of interest.

\section{REFERENCES}

1. Bahar-Fuchs A, Clare L, Woods B. Cognitive training and cognitive rehabilitation for persons with mild to moderate dementia of the Alzheimer's or vascular type: a review.
Alzheimers Res Ther 2013; 5(4): 35 . doi: 10.1186/alzrt189

2. Lenze EJ, Bowie CR. Cognitive training for older adults: what works?. J Am Geriatr Soc 2018;66(4):645-647.

3. Martin $M$, Clare L, Altgassen AM, Cameron $\mathrm{MH}$, Zehnder F. Cognitive-based interventions for healthy older people and people with mild cognitive impairment. Cochrane Database of Systematic Reviews 2011, Issue 1. Art. No.: CD006220. DOI: 10.1002/14651858.CD006220.pub2.

4. Li Ting, Yao Ye, Cheng Y, Xu B, Cao Xinyi, Waxman $D$, et al. Cognitive training can reduce the rate of cognitive aging; a neuroimaging cohort study. BMC Geriatrics 2016;16:12. DOI : 10.1186/s12877-0160194-5

5. Chiu HL, Chu H, Tsai JC, Liu D, Chen YR, Yang $H L$, et al. The effect of cognitive-based training for the healthy older people: a meta-analysis of randomized controlled trials PLoS One 2017;12(5);e0176742. DOI : 10.1371/journal.pone.0176742.

6. Mah L, Szabuniewicz C, Fiocco AJ. Can anxiety damage the brain? Curr Opin Psychiatry 2016; 29:56-63.

7. Diamond K, Mowszowski L, Cockayne N, Norrie L, Paradise M, Hermens DF, et al. Journal of Alzheimer's Disease 2015;44:1181-1191.

8. Belleville $\mathrm{S}$, Hudon $\mathrm{C}$, Bier N, Brodeur C, Gilbert B, Grenier S. et al. MEMO+: Efficacy, Durability and Effect of Cognitive Training and Psychosocial Intervention in Individuals with Mild Cognitive Impairment. J Am Geriatr Soc 2018;66(4):655-663.

9. Wicheantong EU, The effect of memory training program on memory function in the elderly with mild dementia. J Psychiatric Nurs Ment Health 2002;16(2):47-59.

10. Jaiwongphab J, Wrawan P, Boonchai P. The result of using focus group exercise to increase the efficiency of adult's memory based on the concept of Kawashima. J Educ Meas Mahasarakham Univ 2011;17(2):127137. 
11. Nakawiro $D$, Chansirikarnjana $S$, Srisuwan $P$, Aebthaisong O, Sudsakorn P, Vidhyachak C, et al. Group-based training of executive function, attention, memory and visuospatial function (Team-V) in patient with mild neurocognitive disorder. J Psychiatr Assoc Thailand 2017;62(4):337348.

12. Srisuwan $P$, Nakawiro $D$, Chansirikarnjana $S$. Exploring factors that contribute to regular participation and practice in cognitive stimulation training for mild cognitive impairment: A qualitative study. JARH 2017;1(4):1-10. DOI : 10.14302/issn.24747785.jarh-16-1348

13. Sukontapol C, Kemsen S, Chansirikarn S, Nakawiro D, Kuha O, Taemeeyapradit U. The effectiveness of a cogntivie training program in people with mild cognitive impairment: $A$ study in urban community. Asian J Psychiatr 2018;35:18-23.

14. Nilchaikovit $T$, Lortrakul $M$, Phisansuthideth $U$. Development of Thai version of Hospital Anxiety and Depression Scale in cancer patients. J Psychiatr Assoc Thailand 1996;41(1):18-30.

15. Julayanont $P$, Tangwongchai $S$, Hemrungrojn S, Tunvirachaisakul C, Panthumchinda K, Hongsawat J, et al. The montreal cognitive assessment-basic; as creening tool for mild cognitive impairment in illiterate and loweducated elderly adults. J Am Geriatr Soc 2015;63(12):2550-2554.

16. Rosen WG, Mohs RC, Davis KL. A new rating scale for Alzheimer's disease. Am J Psychiatry 1984;141:1356-1364.

17. Mohs RC, Knopman D, Petersen RC, Ferris $\mathrm{SH}$, Ernesto C, Grundman $\mathrm{M}$, et al. Development of cognitive instruments for use in clinical trials of antidementia drugs: additions to Alzheimer's Disease assessment scale that broaden its scope. Alzheimer Dis Assoc Disord 1997;11(Suppl 2):S13-21.

18. Jitapunkul $S$, Kamolratanakul $P$, Ebrahim $S$. The meaning of activities of daily living in a Thai elderly population; development of a new index. Age Ageing 1994;23(2):332-336.
19. Ten Brinke LF, Davis JC, Barha CK, LiuAmbrose T. Effects of computerized cognitive training on neuroimaging outcomes in older adults: a systematic revew BMC Geriatrics 2017;17:139. DOI :10.1186/s12877-017-0529-x

20. Chapman SB, Aslan S, Spence JS, Hart JJ, Bartz EK, Didehbani $\mathrm{N}$, et al. Neural mechnisms of brain plasticity with complex cognitive training in healthy seniors. Cerebral Cortex 2015;25:396-405.

21. Wang $M$, Chang $C$, Su S. What's cooking?Cognitive training of executive function in the elderly. Front Psychol 2011;2:228.doi: 10.3389/fpsyg.2011.00228

22. Wennberg A, Kueider A, Spira A, Adams G, Rager R, Rebok $G$. Online attention training for older adults. Int J Cogn Technol 2014;19(2):13-21.

23. Smith $M$, Jones MP, Dotson MM, Wolinsky FD. Computerized cognitive training to improve mood in senior living settings: design of a randomized controlled trial. Open Access Journal of Clinical Trials 2018;10:29-41.

24. Diamond K, Mowszowski L, Cockayne N, Norrie L, Paradise $M$, Hermens DF, et al. Randomized controlled trial of a healthy brain ageing cognitive training program; effects on memory, mood, and sleep. J Alzheimers Dis 2015;44(4):1181-1191.

25. Kim HJ, Yang Y, Oh JG, Oh $\mathrm{S}$, Choi H, Kim KH, et al. Effectiveness of a community-based multidomain cognitive intervention program in patients with Alzheimer's disease. Geriatr Gerontol Int 2016;16(2):191-199.

26. Jones RN. Cognitive training improves cognitive performances, but what else?. J Am Geriatr Soc 2018;66:648-649.

27. Rebok GW, Ball K, Guey LT, Jones RN, Kim $H Y$, King Jw, et al. Ten-year effects of the ACTIVE cognitive training trial on cognition and everyday functioning in older adults. J Am Geriatr Soc 2014;62(1): 16-24.

28. Giuli $C$, Fattoretti $P$, Gagliardi $C$, Mocchegiani $E$, Venarucci $D$, Balietti $M$, et al. My Mind Project: the effects of cognitive training for 
Patsri Srisuwan et al, International Journal of Medical and Biomedical Studies (IJMBS)

elderly-the study protocol of a prospective randomized intervention study. Aging Clin Exp Res 2017;29(3):353-360. doi: 10.1007/s40520-016-0570-1.

29. Ball $K$, Berch DB, Helmers KF, Jobe JB, Leveck $M D$, Marsiske $M$, et al. Effects of cognitive training interventions with older adults; a randomized controlled trial JAMA 2002;288(18):2271-2281.

30. Baumgart M, Snyder HM, Carrillo MC, Fazio $\mathrm{S}$, Kim $\mathrm{H}$, Johns $\mathrm{H}$. Summary of the evidence on modifiable risk factors for cognitive decline and dementia: a population-based perspective. Alzheimer's \& Dementia 2015;11:718-726. 